\title{
Removal of an oral squamous cell carcinoma including parts of osseointegrated implants in the marginal mandibulectomy. A case report
}

\author{
Gert J. Meijer • Francois J. Dieleman • \\ Stefaan J. Bergé • Matthias A. W. Merkx
}

Published online: 24 February 2010

(C) The Author(s) 2010. This article is published with open access at Springerlink.com

\begin{abstract}
Purpose The incidence of oral squamous cell carcinomas (OSCC) arising around dental implants will increase because of the rising popularity of dental implants. In this case, a novel surgical treatment of an OSCC in the vicinity of endosseous implants is reported.

Materials and methods In a 69-year-old woman, a recurrent OSCC $\left(\mathrm{cT}_{2} \mathrm{~N}_{0} \mathrm{M}_{0}\right)$ developed in the floor of the mouth extending to the attached keratinized peri-implant mucosa of both interforaminal-placed dental implants. Radiographically, no bone invasion could be observed.

Results To radically remove the tumor, a marginal mandibulectomy was performed including the cranial parts of both dental implants by cutting them into two parts. Three years after tumor resection and one year after reimplantation, the patient is disease free and has a good oral function.

Conclusions In case of an OSCC, traditional bone and soft margins for oncologic safety are $1.0 \mathrm{~cm}$. If a dental implant is present within this safety zone, on condition, there is no massive bone invasion, and the original mandible has
\end{abstract}

\begin{tabular}{l}
\hline Sponsors None \\
\hline Competing interests None declared \\
\hline Funding None \\
\hline Ethical approval Not required \\
\hline G. J. Meijer $(\square) \cdot$ F. J. Dieleman $\cdot$ S. J. Bergé $\cdot$ M. A. W. Merkx \\
Department of Oral and Maxillofacial Surgery 590, \\
Radboud University Nijmegen Medical Center, \\
Geert Grooteplein-Zuid 14, \\
6525 GA Nijmegen, the Netherlands \\
e-mail: g.meijer@dent.umcn.nl
\end{tabular}

sufficient vertical height; a marginal mandibulectomy including part of the implants can be considered.

Keywords Oncology · Mandible · Endosseous implants . Prosthodontics $\cdot$ Marginal mandibulectomy

\section{Introduction}

In view of the gaining popularity of oral endosseous implants in general and specifically the extended use of implants in patients with head and neck cancer to give retention to a (partial) dental prosthesis, the issue of malignancies arising in the vicinity of dental implants will be encountered in the future more often $[1,2]$. Primary oral squamous cell carcinomas (OSCC), recurrences, or even second primary tumors may arise in the vicinity of alreadyfunctioning implants. Few reports have been published about this issue [3-13]. Sometimes, their initial clinical appearance suggested peri-implantitis $[4,7,13]$, thereby demonstrating that malignancies can masquerade as a benign peri-implant complication. It has to be emphasized that a high degree of vigilance is required. The majority of all presented cases had at least one recognized risk factor for oral cancer [6], thereby stressing that the carcinogenic role of endosseous implants has never been established [1]. Surgery with postoperative radiotherapy on indication is still the first choice of curative treatment for an OSCC.

Surprisingly, in the literature, the topic of the type of resection when dental implants are adjacent or around the tumor is only limitedly addressed. When no evident bone invasion is present, a simple technique of removing the tumor including the dental implants can be used. 


\section{Case report}

A 65-year-old female, suffering from an OSCC of the right anterior floor of the mouth $\left(\mathrm{pT}_{1} \mathrm{~N}_{2 \mathrm{~b}} \mathrm{M}_{0}\right)$, was treated in November 2002 with a wide excision in combination with a lateral neck dissection at the right side. To achieve radical removal, the lower teeth had to be extracted, and the alveolar process was reduced in height. Subsequently, two endosseous implants (TiUnite Mark III RP, Nobel Biocare ${ }^{\circledR}$, Gothenburg, Sweden) were placed into the symphyseal region of the mandible to facilitate early prosthetic rehabilitation $[1,2]$.

Postoperatively, the patient was subjected to a fractionated radiotherapy schedule up to a cumulative dose of 64 Gy (32 times, receiving 2 Gy at each session) because of a spidery growth pattern and two ipsilateral positive lymph nodes of level Ib. After a healing period of 3 months postradiation, the patient desired prosthetic rehabilitation. Consecutively, healing abutments were placed (June 2002), and a barretained overdenture was fabricated. Since then, this construction functioned satisfactorily for about 4 years without further complications.

Unfortunately, in October 2006, 4 years postradiation, a recurrent OSCC $\left(\mathrm{cT}_{2} \mathrm{~N}_{0} \mathrm{M}_{0}\right)$ developed. Between the two implants, an exophytic tumor was observed in the floor of the mouth extending to the attached keratinized peri-implant mucosa of both implants (Fig. 1a). Radiographically (OPG and CT scan), no osteolytic lesions around the dental implants, indicative for bone invasion, could be observed [14].

To achieve radical removal, first, a tumor-free mucosal margin of $1 \mathrm{~cm}$ was outlined. Subsequently, the mandibular bone surface was exposed by careful elevation of the mucoperiosteum in caudal direction, thereby preserving the attachment of the soft tissue to the aimed cranial bone segment (Fig. 1b). Then, the marginal mandibulectomy was performed, utilizing a standard drill unit (Elan-EC, Aesculap ${ }^{\circledR}$, Tuttlingen, Germany) connected to a saw using a standard saw blade (Braun-Aesculap ${ }^{\circledR}$ sterile blades, Ref GC615R; Tuttlingen, Germany). During the osteotomy, consecutively, the implants were also cut into two parts (Fig. 1c, d).

Postoperatively, the lower denture was not worn for 6 months. The mucosal defect was closed primarily. In addition, the patient was warned of the risk of fracture and instructed about oral hygiene and soft diet. The soft tissues healed well (Fig. 2).

Histology showed a radically removed tumor with an 8-mm free mucosal margin. The tumor had an infiltrative spidery-type growth pattern in the lamina propria. Fortunately, no bone, perineural, or intravascular invasion was observed.

Two years postoperatively (November 2008), it was decided to insert dental implants again. After exposing the mucoperiostal flap, the apical parts of the cut implants could be easily identified (Fig. 3). Three years after resection of the recurrent tumor and 1 year after reimplantation, the patient is disease free and has a good oral function.

\section{Discussion}

Only few previously reported cases of malignancies arising in the vicinity of dental implants have been published [3-13]. Definitely, this number will increase in the future due to two main reasons. Firstly, prosthetic rehabilitation
Fig. 1 a The carcinoma is positioned between the white arrows. b First, an incision is made, respecting a border (see arrows) of $1 \mathrm{~cm}$ around the tumor. c Intraoral view after removing the upper bone segment. Clearly, the apical parts of both implants are visible, as also $\mathbf{d}$ the cervical parts in the block resection (see arrows)
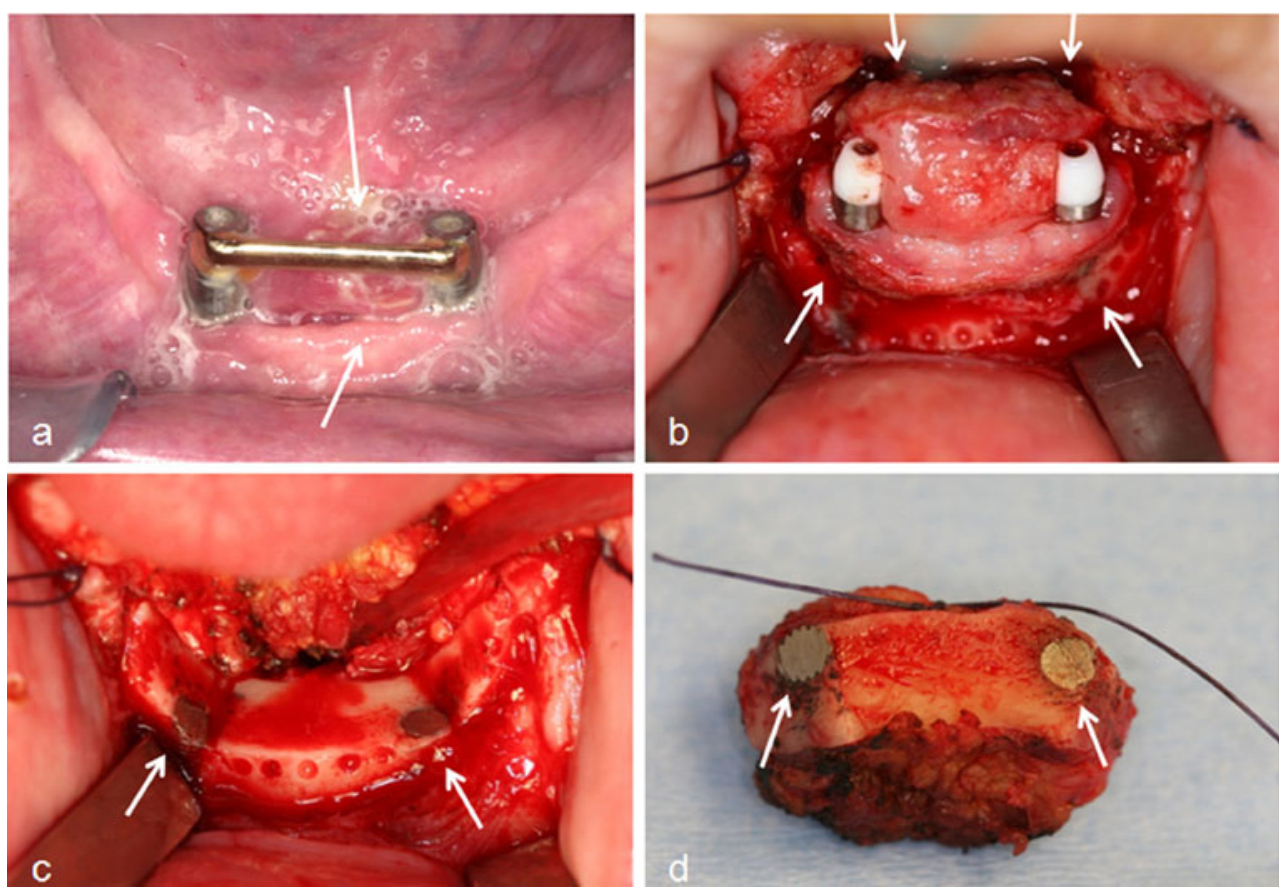
Fig. 2 a Panoramic radiograph preoperatively showing both the implants with their interconnecting bar and $\mathbf{b}$ after resection. Notice the round edges of the osteotomy (white arrows). c Intraoral view 1 year after partial implant removal
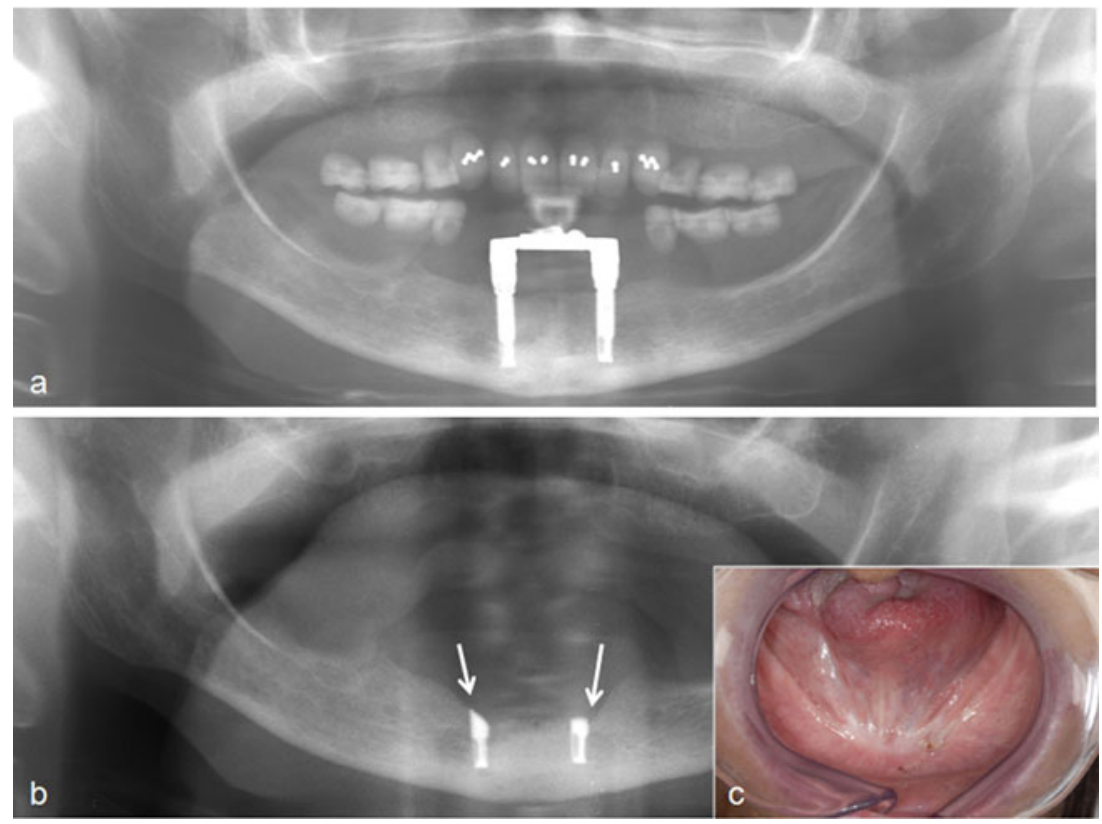

using endosseous implants is gaining in popularity, implicating that, within the group developing an OSCC, more patients will show up with endosseous implants. Secondly, in patients suffering from intraoral carcinomas, there is more and more tendency to install endosseous implants to restore their oral functioning $[1,2]$. The fact that tumor recurrences appear mainly in the first two postoperative

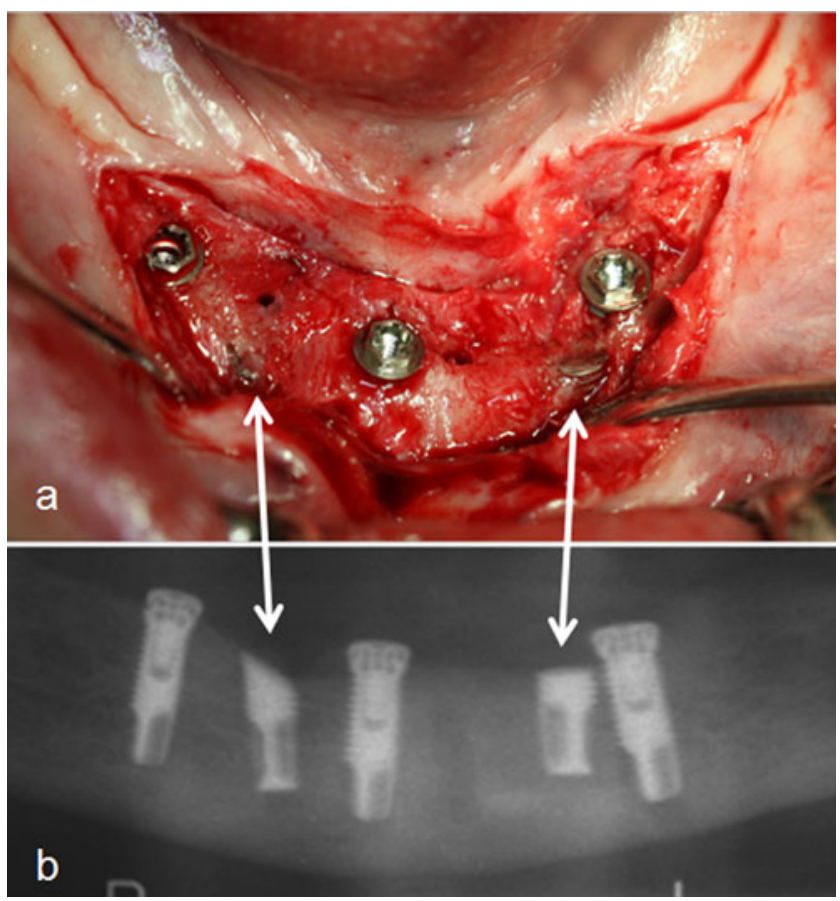

Fig. 3 a Situation after placement of three implants. The cut implants (white arrows) can be easily identified. b Panoramic radiograph postoperatively showing both the new and the cut implants (white arrows) years explains why the phenomenon of a "tumor around endosseous implants" will occur significantly more in the coming years.

Some authors discuss the topic of peri-implant carcinomas first presenting itself as peri-implantitis. They emphasize that, in patients with long-standing and recurring leukoplakia, heavy smoking, and alcohol abuse, a biopsy should be taken $[4,7,13]$. Obviously, if the patient already has a history of malignancy, each oral lesion, including peri-implantitis, is a suspect for carcinoma.

A literature search yielded 11 previously documented cases of malignancy adjacent to implants [3-13]. No papers emphasize that osseointegrated implants have been clearly identified as a potential route of entry for OSCC into the mandible. However, one report illustrated an OSCC that occurred in relation to osseointegrated implants, showing the apparent invasion of the mandibular alveolus by tumor along the line of the implant fixture [12].

To our knowledge, this is the first report that describes the removal of implants in the vicinity of an OSCC by cutting them consecutively during the marginal mandibulectomy. To remove an osseointegrated implant, alternatively, with round or hollow cylinder burrs, a gap could be prepared around the implant. From an oncological point of view, this approach is undesired with respect to tumor spill/ spread. Moreover, removing an implant in total creates a gap in the mandibular bone, increasing significantly the risk of mandibular fractures. In case of a total mandibulectomy, an extensive reconstruction of the anterior mandible would be mandatory. Surprisingly, this sawing procedure was much easier than expected, thereby leaving the apical parts in the lower mandibular bone segment (Fig. 1d). The residual vertical mandibular height was $11 \mathrm{~mm}$. It should be 
emphasized that sharp edges between the horizontal and vertical bone cuts have to be avoided, as these may lead to fractures [15].

In case of an OSCC, traditional bone and soft margins for oncologic safety are $1.0 \mathrm{~cm}$. In the anterior mandible, a marginal mandibulectomy is only indicated when there is sufficient height of the inferior border present. To limit the risk of pathologic fracture, at least a residual vertical bone height of $10 \mathrm{~mm}$ should be left. This method allows radical removal of the tumor, without the direct need of performing a more invasive segmental mandibulectomy. However, if radiographically bone resorption around the implants is observed, indicative for tumor invasion, a more radical surgical approach (e.g., segmental resection) is indicated.

Open Access This article is distributed under the terms of the Creative Commons Attribution Noncommercial License which permits any noncommercial use, distribution, and reproduction in any medium, provided the original author(s) and source are credited.

\section{References}

1. Schepers RH, Slagter AP, Kaanders JH, van den Hoogen FJ, Merkx MA (2006) Effect of postoperative radiotherapy on the functional result of implants placed during ablative surgery for oral cancer. Int J Oral Maxillofac Surg 35:803-808

2. Schoen PJ, Raghoebar GM, Bouma J, Reintsema H, Burlage FR, Roodenburg JL, Vissink A (2008) Prosthodontic rehabilitation of oral function in head-neck cancer patients with dental implants placed simultaneously during ablative tumor surgery: an assessment of treatment outcomes and quality of life. Int J Oral Maxillofac Surg $37: 8-16$

3. Abu El-Naaj I, Trost O, Tagger-Green N, Trouilloud P, Robe N, Malka G, Peled M (2007) Peri-implantitis or squamous cell carcinoma? Rev Stomatol Chir Maxillofac 108:458-460
4. Block MS, Scheufler E (2001) Squamous cell carcinoma appearing as peri-implant bone loss: a case report. J Oral Maxillofac Surg 59:1349-1352

5. Clapp C, Wheeler JC, Martof AB, Levine PA (1996) Oral squamous cell carcinoma in association with dental osseointegrated implants. An unusual occurrence. Arch Otolaryngol Head Neck Surg 122:1402-1403

6. Czerninski R, Kaplan I, Almoznino G, Maly A, Regev E (2006) Oral squamous cell carcinoma around dental implants. Quintessence Int 37:707-711

7. Eguia del Valle A, Martínez-Conde Llamosas R, López Vicente J, Uribarri Etxebarria A, Aguirre Urizar JM (2008) Primary oral squamous cell carcinoma arising around dental osseointegrated implants mimicking peri-implantitis. Med Oral Patol Oral Cir Bucal 13:489-491

8. Friedman KE, Vernon SE (1983) Squamous cell carcinoma developing in conjunction with a mandibular staple bone plate. $\mathrm{J}$ Oral Maxillofac Surg 41:265-266

9. Gallego L, Junquera L, Baladrón J, Villarreal P (2008) Oral squamous cell carcinoma associated with symphyseal dental implants: an unusual case report. J Am Dent Assoc 139:10611065

10. Kwok J, Eyeson J, Thompson I, McGurk M (2008) Dental implants and squamous cell carcinoma in the at risk patientreport of three cases. Br Dent J 205:543-545

11. Moxley JE, Stoelinga PJ, Blijdorp PA (1997) Squamous cell carcinoma associated with a mandibular staple implant. J Oral Maxillofac Surg 55:1020-1022

12. Schache A, Thavaraj S, Kalavrezos N (2008) Osseointegrated implants: a potential route of entry for squamous cell carcinoma of the mandible. Br J Oral Maxillofac Surg 46:397-399

13. Shaw R, Sutton D, Brown J, Cawood J (2004) Further malignancy in field change adjacent to osseointegrated implants. Int $\mathrm{J}$ Oral Maxillofac Surg 33:353-355

14. Van Cann EM, Koole R, Oyen WJ, de Rooy JW, de Wilde PC, Slootweg PJ, Schipper M, Merkx MA, Stoelinga PJ (2008) Assessment of mandibular invasion of squamous cell carcinoma by various modes of imaging: constructing a diagnostic algorithm. Int J Oral Maxillofac Surg 37:535-541

15. Wittkampf ARM, Witkampf FJM (1995) Prevention of mandibular fractures by using constructional design principles: part I. Int J Oral Maxillofac Surg 24:306 